University of Nebraska - Lincoln

DigitalCommons@University of Nebraska - Lincoln

\title{
Plasmodium vivax. allele variants of the $m d r 1$ gene do not associate with chloroquine resistance among isolates from Brazil, Papua, and monkey-adapted strains
}

\author{
Juliana Martha Sá \\ Universidade de Sao Paulo \\ Takashi Nomura \\ National Institutes of Health \\ Joana D'Arc Neves \\ Centro de Pesquisa em Medicina Tropical \\ J. Kevin Baird \\ U.S. Naval Medical Research Unit \# 2, jkevinbaird@yahoo.com \\ Thomas E. Wellems \\ National Intitutes of Health \\ See next page for additional authors
}

Follow this and additional works at: https://digitalcommons.unl.edu/usnavyresearch

Sá, Juliana Martha; Nomura, Takashi; D'Arc Neves, Joana; Baird, J. Kevin; Wellems, Thomas E.; and del Portillo, Hernando A., "Plasmodium vivax. allele variants of the $m d r 1$ gene do not associate with chloroquine resistance among isolates from Brazil, Papua, and monkey-adapted strains" (2005). U.S. Navy Research. 66.

https://digitalcommons.unl.edu/usnavyresearch/66

This Article is brought to you for free and open access by the U.S. Department of Defense at DigitalCommons@University of Nebraska - Lincoln. It has been accepted for inclusion in U.S. Navy Research by an authorized administrator of DigitalCommons@University of Nebraska - Lincoln. 


\section{Authors}

Juliana Martha Sá, Takashi Nomura, Joana D'Arc Neves, J. Kevin Baird, Thomas E. Wellems, and Hernando A. del Portillo 


\title{
Plasmodium vivax: allele variants of the $m d r 1$ gene do not associate with chloroquine resistance among isolates from Brazil, Papua, and monkey-adapted strains
}

\author{
Juliana Martha Sáa, Takashi Nomura ${ }^{\mathrm{b}}$, Joana d'Arc Neves ${ }^{\mathrm{c}}$, J. Kevin Baird ${ }^{\mathrm{d}}$, \\ Thomas E. Wellems ${ }^{\mathrm{b}}$, Hernando A. del Portillo ${ }^{\mathrm{a}, *}$ \\ ${ }^{a}$ Departamento de Parasitologia, Instituto de Ciências Biomédicas, Universidade de São Paulo, Av. Lineu Prestes 1374, \\ São Paulo SP, 05508-900, Brazil \\ ${ }^{\mathrm{b}}$ Malaria Genetics Section, Laboratory of Malaria and Vector Research, National Institute of Allergy and Infectious Diseases, NIH, USA \\ ${ }^{\mathrm{c}}$ Centro de Pesquisa em Medicina Tropical (CEPEM), Porto Velho, Rondônia, Brazil \\ ${ }^{\mathrm{d}}$ US Naval Medical Research Unit No.2, Jakarta, Indonesia
}

Received 15 July 2004; received in revised form 29 November 2004; accepted 3 December 2004

\begin{abstract}
We describe here the sequence of the Plasmodium vivax mdr1 gene from 10 different isolates differing in chloroquine sensitivity. The deduced amino acid sequence of PvMDR1 shares more than $70 \%$ similarity with other malarial MDR proteins and it displays consensus motifs of an ABC family transporter including two transmembrane domains and two ATP binding cassettes. Similarity and dendrogram analyses revealed that sequences could be grouped according to their geographical origin. Within each geographical group however, no correlation was found between chloroquine resistance and specific mutations.
\end{abstract}

(c) 2005 Elsevier Inc. All rights reserved.

Keywords: Plasmodium vivax; mdrl genes; ABC family transporters; Chloroquine resistance; Allele variants

Plasmodium vivax is the most widely distributed human malarial parasite outside sub-Saharan Africa and responsible for 70-80 million clinical cases annually (Mendis et al., 2001). Despite its major socioeconomical burden, research in $P$. vivax remains largely neglected due to the lack of a continuous in vitro culture and the low parasitemias associated with natural infections.

Drug resistance is a major factor in the present resurgence of malaria worldwide. Several genes have now been related to drug resistance in Plasmodium falciparum, which causes the most lethal form of human malaria: $p f d h f r$ and $p f d h p s$, where point mutations confer resistance to dihydrofolate reductase inhibitors (Cowman et al., 1988; Peterson et al., 1988) and sulfadoxine (Brooks et al., 1994; Triglia and Cowman, 1994), respectively; cytochrome $b$ gene in which the point mutation Y268S can be rapidly selected by atovaquone monotherapy (Korsinczky et al., 2000; Srivastava and Vaidya, 1999); pfcrt, which contains specific mutations associated with chloroquine resistance

\footnotetext{
${ }^{*}$ Corresponding author. Fax: +55 1130917417.

E-mail address: hernando@icb.usp.br (H.A. del Portillo).
}

(CQR) (Fidock et al., 2000); $p f m d r 1$ and $p f m d r 2$ which encode P-glycoproteins from the ABC (ATP binding cassette) transporters family (Foote et al., 1989; Wilson et al., 1989; Zalis et al., 1993), and some other transporters that may be involved in chloroquine and quinine resistance (Mu et al., 2003).

Orthologous genes of $p f d h f r$ and pfcrt have been described in P. vivax, namely pvdhfr (Eldin de Pecoulas et al., 1998), where point mutations are also associated with resistance against dihydrofolate reductase inhibitors, and pvcg10 (Nomura et al., 2001), which in contrast to pfcrt contains no specific mutations associated with chloroquine resistance (CQR). The purpose of this work was to identify the ortholog of $p f m d r l$ in $P$. vivax, to establish its primary structure and to verify whether amino acid substitutions were associated with CQR among isolates from different regions of the world displaying different phenotypes of chloroquine sensitivity.

To identify $P$. vivax $m d r$ genes, the oligonucleotides 5'-ATGA AAAAGGATCAAAGGCAAC-3' (forward) and 5'-CTACTTAGC CAGCTTGACGTAC-3' (reverse) were used in PCR amplifications of $P$. vivax genomic DNA from 10 different chloroquine sensitive (CQS) and chloroquine resistant (CQR) isolates or strains from differ- 
ent geographical regions. Thus, three samples were from the Brazilian Amazon State of Rondônia (RO14, RO19, ROB2, and all CQS), one sample was from El Salvador in Central America (SalI, CQS), one from Papua New Guinea (NGIV, CQS), one from Indonesia (IndoF, CQR), and four from Papua (CL001, CQS; CL004, CQR; CL007, CQS; and CL014, CQR). Thirty-five PCR cycles were performed, each consisting of denaturation for $30 \mathrm{~s}$ at $94{ }^{\circ} \mathrm{C}$, renaturation for $30 \mathrm{~s}$ at $45^{\circ} \mathrm{C}$, and elongation for $5 \mathrm{~min}$ at $68^{\circ} \mathrm{C}$ using elongase (Invitrogen). Unique $4.5 \mathrm{~kb}$ DNA fragments were amplified from all samples, cloned in pGEM T-easy plasmids (Promega) and sequenced using an ABI3100 automatic sequencer (Applied Biosystems). Chromatograms and contigs were evaluated and assembled using the Phred-Phrap-Con- sed program (http://www.phrap.org/). To guarantee the authenticity of these sequences, all sequences were assigned a Phred value above 40. Moreover, polymorphisms were confirmed by sequencing independent amplifications to exclude PCR artifacts. Synteny was examined using the ACT tool (http://www.sanger.ac.uk/Software/ACT/), and comparing a $P$. vivax contig containing the $P$. vivax $\mathrm{mdr}$ sequences obtained from the $P$. vivax genome project at TIGR (http://www.tigr. org/tdb/e2k1/pva1/) with the $P$. falciparum genome as annotated in PlasmoDB (http://plasmodb.org/). GenBank Accession Nos: CL001 AY571975, CL004 AY571976, CL007 AY571977, CL014 AY571978, IndoF_H4 AY571979, NGIV_H7 AY571980, RO14 AY571981, RO19 AY571982, ROB2 AY571983, and SalI AY571984.
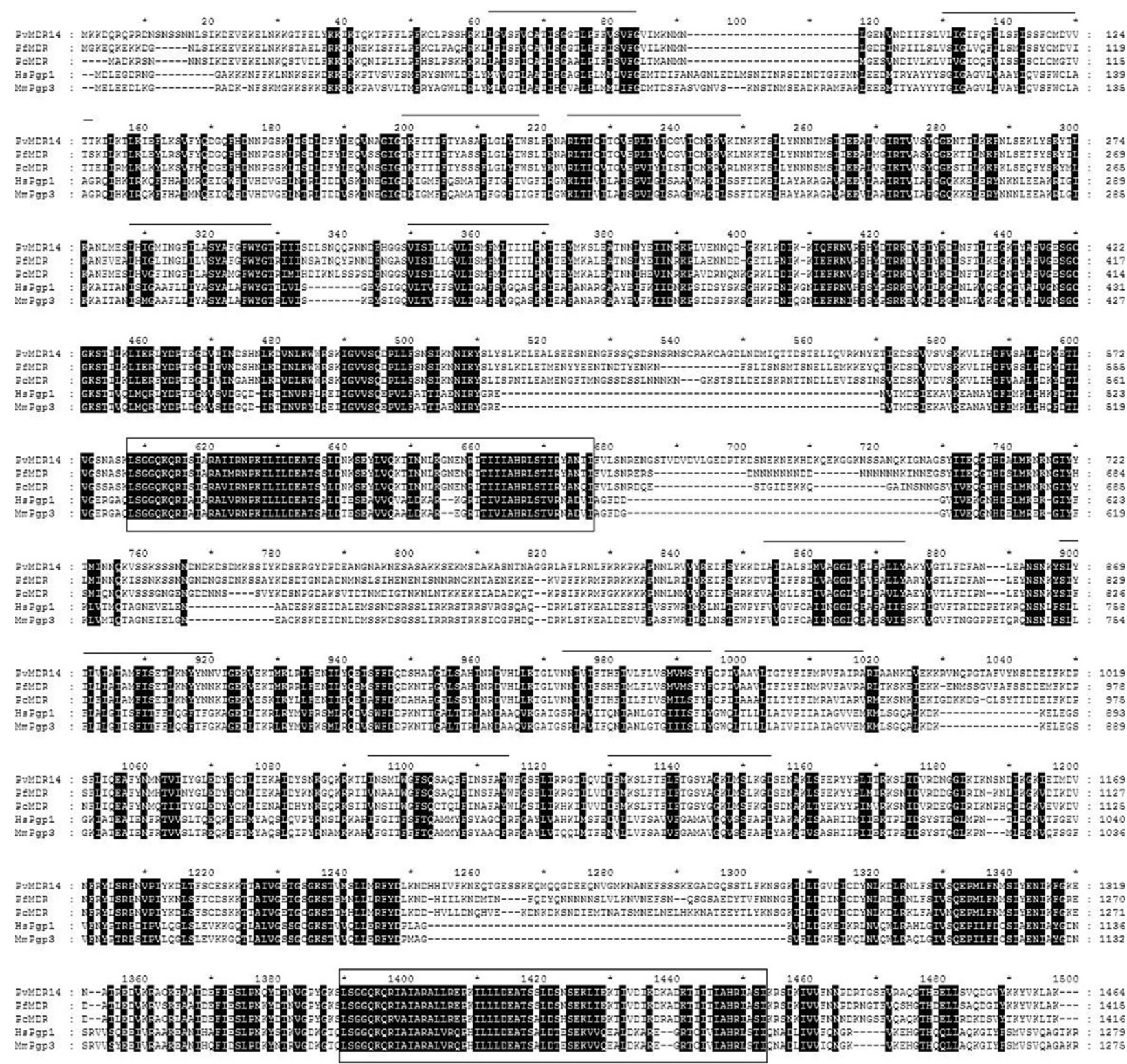

Fig. 1. Amino acid sequence comparisons of PvMDR1 and related MDR proteins. Deduced amino acid sequence of PvMDR1 from a $P$. vivax isolate (pvmdr14-Accession No. AY571981) compared to MDR homologues of P. falciparum (pfmdr-Accession No. NP703574), P. chabaudi ( $p c m d r$-Accession No. AAM82617) and Pgp1, one of the human MDR proteins (Accession No. NP000918) and MDR3, of mouse (Accession No. P21447). Sequences were aligned using the ClustalX program (ftp://ftp-igbmc.ustrasbg.fr/pub/ClustalX/). Predicted Transmembrane regions were predicated with the SOUSI (Classification and Secondary Structure Prediction of Membrane Proteins) program (http://sosui.proteome. bio.tuat.ac.jp/sosuiframe $0 . \mathrm{html}$ ) and are shown with a line over the correspondent sequence. Black shading highlights both conserved residues and those where the amino acid substitutions are conservative. Boxes enclose potential nucleotide binding consensus sequences. 


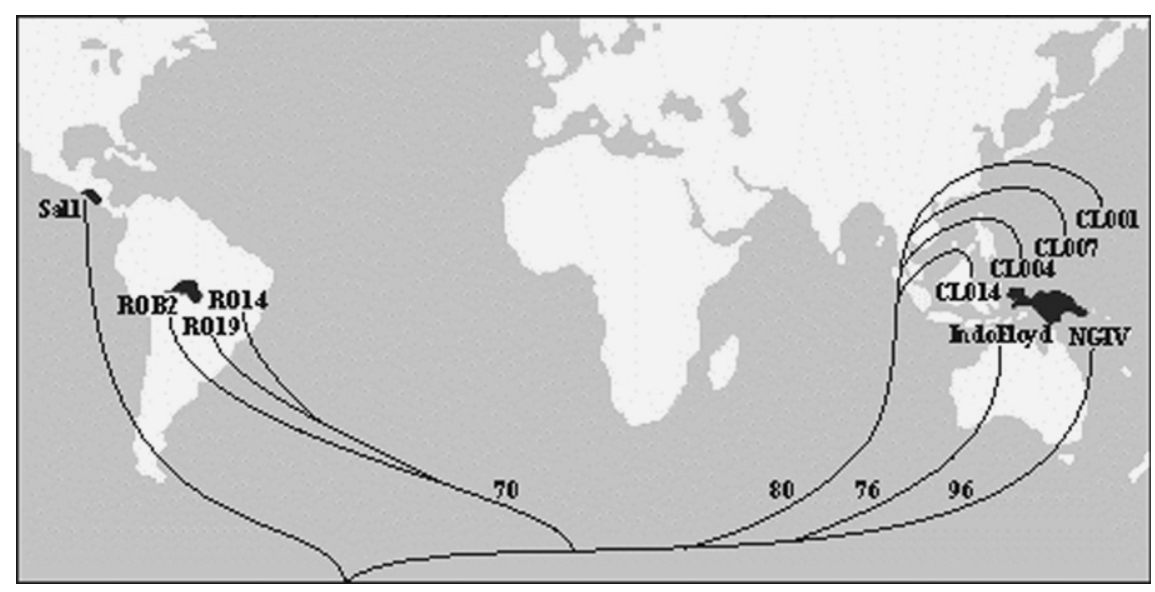

Fig. 2. Phylogenetic tree and geographic distribution of pvmdrl allele variants. A phylogenetic tree based on sequence alignments of deduced amino acid sequences from putative PvMDR1 of all 10 isolates was generated using Molecular Evolutionary Genetics Analysis, MEGA, software version 2.1 (http://www.megasoftware.net/text/news.sht). This tree was adapted to display the geographical distribution of the samples. The neighborjoining model was used to construct the bootstrap consensus tree (1000 replicates used to estimate the standard error) with distance option of amino acids number of differences. Shaded areas represent the geographical origin of the different samples.

BLASTn analysis against PlasmoDB revealed that the sequences from all isolates shared more than $70 \%$ similarities with the $P$. falciparum mdrl gene located on chromosome 5. Furthermore, deduced amino acid sequences indicated an open reading frame of 4395 nucleotides encoding a protein with predicted molecular mass of approximated 165,000 Da. BLASTP analysis showed 70, 63, and 64\% similarities with predicted proteins from $P$. falciparum (Accession No. AAA29646.1), $P$. chabaudi (Accession No. AAM82617.1) and $P$. yoelii MDR1 (Accession No. EAA22011), respectively. This analysis also revealed the presence of conserved nucleotide binding sites (NBS) of the ATP binding cassette $(\mathrm{ABC})$ protein family in two halves of the molecule each of which also contained 12 predicted membrane-spanning domains (Fig. 1). Multiple sequence alignments including MDR protein sequences from $P$. falciparum, $P$. chabaudi, and $\mathrm{ABC}$ transporters from Drosophila melanogaster (CG10226-PA) and human (NP 061337.1), further confirmed that the $P$. vivax sequences pertain to the $\mathrm{ABC}$ protein family (Fig. 1). Moreover, using the last released version of the TIGR P. vivax genome project, a 307,346 bp contig containing the $P$. vivax $m d r$ sequences was identified and compared to the homologous region of the $P$. falciparum genome using the ACT tool. The results demonstrated a large degree of synteny of this genome region between these two human malaria parasite species (not shown). Together these data strongly suggest that this $P$. vivax gene encodes a P-glycoprotein orthologue of $p f m d r l$ and accordingly we have termed it pvmdr1.

Chloroquine is still the primary chemotherapeutic drug for treatment of $P$. vivax but unfortunately resistance is emerging in several malaria regions of the world (Wellems and Plowe, 2001). To determine whether an association exists between point mutations of the pvmdrl gene and CQR, similarity and dendrogram analyses were performed using pvmdrl sequences from isolates of different geographical regions and with different chloroquine response (Fig. 2). Interestingly, these analyses revealed that sequences could be grouped according to their geographical origin and that within each geographical group resistant isolates branched independently; yet, there was no association of amino acid substitutions with CQR.

Knowledge about genetic diversity and population structure of $P$. vivax remains limited (Cui et al., 2003). Studies on gene diversity and population structure will help in predicting and monitoring the effectiveness of intervention strategies such as the usefulness of therapeutic regimens, the dispersion of drug resistance, and the emergence of multidrug-resistant parasites. For example, a direct correlation of pvdhfr point mutations from four different allelic variants with pyrimethamine resistance and geographic distribution of $P$. vivax, has been reported (Imwong et al., 2001). In contrast, no association has been found between point mutations of the $P$. vivax homolog gene of the $P$. falciparum $\mathrm{CRT}$ and the chloroquine response of different $P$. vivax isolates, including some of the samples used in the present work (Nomura et al., 2001). Similarly, our results failed to detect a correlation of pvmdrl allele variants and CQR and are thus in agreement with results that have not linked polymorphism of the P. falciparum $m d r l$ gene with chloroquine resistance (Wellems et al., 1990). The mechanism of $\mathrm{CQR}$ in P. vivax remains to be determined.

There is presently no consensus definition of drug resistance in $P$. vivax; yet, it is clear that chloroquine resistance and multiple drug resistance will spread. Genes related to pyrimethamine resistance, pvdhfr (Eldin de Pecoulas et al., 1998; Imwong et al., 2001), chloroquine resistance, pvcg10 (Nomura et al., 2001) and multiple drug resistance, pvmdrl (the present work) have been characterized in $P$. vivax. With the imminent release of the $P$. vivax genome (http://www. tigr.org/tdb/e2k1/pva1/), and annotations facilitated through ESTs gene discovery (Merino et al., 2003), it is likely that in silico analysis will predict additional transporter and drug resistance genes as has been recently reported for P. falciparum (Mu et al., 2003). Along with the development of new technologies for $P$. vivax such as the shortterm in vitro cultures to monitor drug-resistance (Chotivanich et al., 2004) it is hoped that monitoring and control strategies will help control worldwide spread of multiple drug resistant $P$. vivax parasites.

\section{Acknowledgments}

We are grateful to Prof. Luiz H. Pereira da Silva (CEPEM, Centro de Pesquisas em Medicina Tropical, Rondonia, Brazil) for facilities and to Drs. William E. Collins (Centers for Disease Control and Prevention, Chamblee, GA, USA) and Juan M. Villalobos (CEPEM, Centro de Pesquisas em Medicina Tropical, Rondonia, Brazil) for P. vivax isolates. To Drs. Jianbing Mu, Emilio Fernando Merino and Alan Durham for help with in silico analysis. To Mr. Cassiano Pereira Nunes for the drawing in Fig. 2, to Ms. Vanessa Fonseca Tumilasci for automatic sequencing and to Mr. Marcio Massao Yamamoto for technical assistance. J.M.S. is a graduate student supported by "Fundação de Amparo à Pesquisa do Estado de São Paulo" FAPESP (ID 
No 01/09746-8). This work was supported by FAPESP (ID 01/094010 ) and "Conselho Nacional de Desenvolvimento Científico e Tecnológico" CNPq (ID 302572/2002-3).

\section{Appendix A. Supplementary data}

Supplementary data associated with this article can be found, in the online version, at doi:10.1016/j.exppara.2004.12.005.

\section{References}

Brooks, D.R., Wang, P., Read, M., Watkins, W.M., Sims, P.F., Hyde, J.E., 1994. Sequence variation of the hydroxymethyl dihydropterin pyrophosphate kinase: dihydropteroate synthase gene in lines of the human malaria parasite, Plasmodium falciparum, with differing resistance to sulfadoxine. Eur. J. Biochem. 224, 397-405.

Cowman, A.F., Morry, M.J., Biggs, B.A., Cross, G.A., Foote, S.J., 1988. Amino acid changes linked to pyrimethamine resistance in the dihydrofolate reductase-thymidylate synthase gene of Plasmodium falciparum. Proc. Natl. Acad. Sci. USA 85, 9109-9113.

Cui, L., Escalante, A.A., Imwong, M., Snounou, G., 2003. The genetic diversity of Plasmodium vivax populations. Trends Parasitol. 19, 220-226.

Chotivanich, K., Udomsangpetch, R., Chierakul, W., Newton, P.N., Ruangveerayuth, R., Pukrittayakamee, S., Looareesuwan, S., White, N.J., 2004. In vitro efficacy of antimalarial drugs against Plasmodium vivax on the western border of Thailand. Am. J. Trop. Med. Hyg. 70, 395-397.

Eldin de Pecoulas, P., Basco, L.K., Tahar, R., Ouatas, T., Mazabraud, A., 1998. Analysis of the Plasmodium vivax dihydrofolate reductase-thymidylate synthase gene sequence. Gene 211, 177-185.

Fidock, D.A., Nomura, T., Talley, A.K., Cooper, R.A., Dzekunov, S.M., Ferdig, M.T., Ursos, L.M., Sidhu, A.B., Naude, B., Deitsch, K.W., Su, X.Z., Wootton, J.C., Roepe, P.D., Wellems, T.E., 2000. Mutations in the $P$. falciparum digestive vacuole transmembrane protein PfCRT and evidence for their role in chloroquine resistance. Mol. Cell 6, 861-871.

Foote, S.J., Thompson, J.K., Cowman, A.F., Kemp, D.J., 1989 Amplification of multi-drug resistance gene in some chloroquineresistant isolates of $P$. falciparum. Cell 57, 921-930.

Imwong, M., Pukrittakayamee, S., Looareesuwan, S., Pasvol, G., Poirreiz, J., White, N.J., Snounou, G., 2001. Association of genetic mutations in Plasmodium vivax dhfr with resistance to sulfadoxine- pyrimethamine: geographical and clinical correlates. Antimicrob. Agents Chemother. 45, 3122-3127.

Korsinczky, M., Chen, N., Kotecka, B., Saul, A, Rieckmann, K., Cheng, Q., 2000. Mutations in Plasmodium falciparum cytochrome $b$ that are associated with atovaquone resistance are located at putative drug-binding site. Antimicrob. Agents Chemothr. 44, 2100-2108

Mendis, K.N., Sina, B.J., Marchesini, P., Carter, R., 2001. The neglected burden of Plasmodium vivax malaria. Am. J. Trop. Med. Hyg. 64, 97-106.

Merino, E.F., Fernandez-Becerra, C., Madeira, A., Machado, A.L., Durham, A., Gruber, A., Hall, N., del Portillo, H.A., 2003. Pilot survey of expressed sequence tags (ESTs) from the asexual blood stages of Plasmodium vivax in human patients. Malar J. 2, 21.

$\mathrm{Mu}$, J., Ferdig, M.T., Feng, X., Joy, D.A., Duan, J., Furuya, T., Subramanian, G., Aravind, L., Cooper, R.A., Wootton, J.C., Xiong, M., Su, X.Z., 2003. Multiple transporters associated with malaria parasite responses to chloroquine and quinine. Mol. Microbiol. 49, 977-989.

Nomura, T., Carlton, J.M., Baird, J.K., del Portillo, H.A., Fryauff, D.J., Rathore, D., Fidock, D.A., Su, X., Collins, W.E., McCutchan, T.F., Wootton, J.C., Wellems, T.E., 2001. Evidence for different mechanisms of chloroquine resistance in 2 plasmodium species that cause human malaria. J. Infect. Dis. 183, 1653-1661.

Peterson, D.S., Walliker, D., Wellems, T.E., 1988. Evidence that a point mutation in dihydrofolate reductase-thymidylate synthase confers resistance to pyrimethamine in falciparum malaria. Proc. Natl. Acad. Sci. USA 85, 9114-9118.

Srivastava, I.K., Vaidya, A.B., 1999. A mechanism for synergistic antimalarial action of atovaquone and proguanil. Antimicrob. Agents Chemother. 43, 1334-1339.

Triglia, T., Cowman, A.F., 1994. Primary structure and expression of the dihydropteroate synthase gene of Plasmodium falciparum. Proc. Natl. Acad. Sci. USA 91, 7149-7153.

Wellems, T.E., Panton, L.J., Gluzman, I.Y., do Rosario, V.E., Gwadz, R.W., Walker-Jonah, A., Krogstad, D.J., 1990. Chloroquine resistance not linked to $m d r$-like genes in a Plasmodium falciparum cross. Nature 345, 253-255.

Wellems, T.E., Plowe, C.V., 2001. Chloroquine-resistant malaria. J. Infect. Dis. 184, 770-776.

Wilson, C.M., Serrano, A.E., Wasley, A., Bogenschutz, M.P., Shankar, A.H., Wirth, D.F., 1989. Amplification of a gene related to mammalian mdr genes in drug-resistant Plasmodium falciparum. Science 244, 1184-1186.

Zalis, M.G., Wilson, C.M., Zhang, Y., Wirth, D.F., 1993. Characterization of the pfmdr2 gene for Plasmodium falciparum. Mol. Biochem. Parasitol. 62, 83-92. 
Table 1S. Pv MDR1 amino acid substitutions and chloroquine phenotypes of the Plasmodium vivax isolates. $\mathrm{CQ}$, chloroquine; $\mathrm{CQS}$, chloroquine sensitive; $\mathrm{CQR}$, chloroquine resistant.

\begin{tabular}{lccccccccccccccccc} 
Isolate & 196 & $\mathbf{2 3 7}$ & $\mathbf{4 4 3}$ & $\mathbf{5 0 0}$ & $\mathbf{5 1 1}$ & $\mathbf{5 5 6}$ & $\mathbf{6 9 8}$ & $\mathbf{7 8 3}$ & $\mathbf{8 2 3}$ & $\mathbf{9 0 8}$ & $\mathbf{9 5 8}$ & $\mathbf{9 7 6}$ & $\mathbf{1 0 7 6}$ & $\mathbf{1 1 0 4}$ & $\mathbf{1 4 4 0}$ & $\mathbf{1 4 4 7}$ & $\begin{array}{c}\text { CQ } \\
\text { phenotype }\end{array}$ \\
\hline RO14 & N & S & I & N & R & V & G & A & K & L & M & Y & F & L & R & E & CQS \\
RO19 & N & S & I & N & R & V & G & A & K & L & M & Y & F & L & Q & E & CQS \\
ROB2 & N & S & I & D & R & V & G & A & K & L & M & Y & F & L & Q & E & CQS \\
Sal1 & N & S & I & D & R & V & G & A & K & M & T & Y & F & L & Q & E & CQS \\
NGIV & N & S & I & D & R & V & S & V & K & L & M & F & L & L & Q & E & CQS \\
IndoF & N & S & I & D & H & V & S & A & K & L & M & F & L & L & Q & E & CQR \\
CL004 & N & S & I & D & H & V & S & A & E & L & M & F & L & F & Q & E & CQR \\
CL014 & N & S & I & D & H & V & S & A & E & L & M & F & L & F & Q & E & CQR \\
CL001 & S & P & T & D & H & V & S & A & E & L & M & F & L & F & Q & G & CQS \\
CL007 & N & S & I & D & H & A & S & A & E & L & M & F & L & F & Q & E & CQS
\end{tabular}

